\title{
Paraplegia Following a Thoracolumbar Transforaminal EPIDURAL STEROId INJECTION
}

\author{
Scott E. Glaser, MD, and Frank Falco, MD
}

\begin{abstract}
Background: In recent years, transforaminal epidural injections have emerged as an alternative to interlaminar and caudal epidural steroid injections. The rationale for utilizing transforaminal epidural injections has been described for diagnostic as well as therapeutic purposes. The evidence for lumbar transforaminal epidural steroid injections in managing lumbar nerve root pain is strong, whereas it is moderate in managing cervical nerve root pain. However, these techniques are also associated with rare, but catastrophic, neurologic complications.

Objective: To present a case report describing a devastating neurologic injury following a transforaminal thoracolumbar epidural steroid injection.
\end{abstract}

Case Report: A 67-year-old female was referred for treatment of chest wall pain following a T-12 compression fracture. Her pain was primarily radicular in nature. She had not responded to conservative care and continued to suffer from disabling pain. A left T12-L1 transforaminal epidural steroid injection was performed using the "safe triangle" technique; there was appropriate spread of dye that was visualized and recorded as well as a "washout" image. The injectate consisted of a $3 \mathrm{~mL}$ volume of $1 \%$ ropivacaine and $50 \mathrm{mg}$ triamcinolone acetonide suspension. The patient experienced a rapid and complete loss of sensation and movement below the $\mathrm{T}-10$ level within five minutes after the injection. An MRI initially performed six hours after the procedure was non-diagnostic but an MRI performed two days later confirmed a thoracolumbar spinal cord infarction. High dose intravenous steroids provided during the course of treatment did not significantly alter her neurological deficits and she continues to be paraplegic.

Conclusion: This case report describes vascular injury leading to an infarction of the spinal cord following a thoracolumbar transforaminal epidural steroid injection. Alternative approaches to, or alternatives means of, performing transforaminal injections should be considered to avoid devastating neurological complications.

Keywords: Complications, epidurals, transforaminal, spinal cord injury, radiculomedullary artery, Artery of Adamkiewicz.

pain. These conclusions were based on extensive review of the literature with inclusion of multiple randomized and nonrandomized evaluations, with studies including lumbar and cervical nerve root pain (6-17).

Transforaminal epidural injections are also associated with multiple potential complications, including intravascular injection, air embolism, vascular trauma, particulate embolism, cerebral thrombosis, epidural hematoma, and neural or spinal cord damage (1, 18-29).

Paraplegia following three separate lumbar transforaminal epidural steroid injections has been described in the literature (18); however, no details of the procedures or fluoroscopic images were provided. Paraplegia following a left L12 transforaminal epidural steroid injection also has been reported (29), although there were no fluoroscopic images despite a more detailed description of the procedure. Three accounts of acute paraplegia following left lower thoracic transforaminal epidural steroid injections employing the "safe triangle" technique also have been published (30) without fluoroscopic images. There are no case reports of paraplegia after a thoracolumbar transforaminal epidural steroid injection.

The following case report involves a case of paraplegia following a left-sided T12-L1 transforaminal epidural steroid injection using the "safe triangle" technique. This is an important case as the injection of radiopaque contrast at no time revealed arterial dispersal. Additionally, the flow pattern of contrast along the nerve root as well as the "washout" picture was consistent with an extra-vascular needle tip/bevel location.

\section{Case Report}

The patient, a 67-year-old female, was referred for treatment of chronic chest wall pain of six months duration after suffering a T-12 compression fracture. The pain did not respond to the administration of multiple opioids, NSAIDs, a tient had difficulty walking, sitting, laying down, and sleeping secondary to the pain. She described the pain as primariTENS unit, or physical therapy. The pa-
Manuscript received on 3/17/2005

Revision submitted on 6/19/2005

Accepted for publication on $6 / 19 / 2005$ 
ly left-sided radiating chest wall pain with numbness extending in a pattern consistent with a T12 distribution around the chest wall and flank. A CT scan performed after the injury revealed a T12 vertebral compression fracture with mild retropulsion and anterior wedging. Secondary to the pain, she could not tolerate lying still long enough for an MRI. She opted to have a transforaminal epidural steroid injection after discussing the treatment options.

A $22 \mathrm{~g}, 3 \frac{1}{2} 2$-inch, spinal needle (Espo-

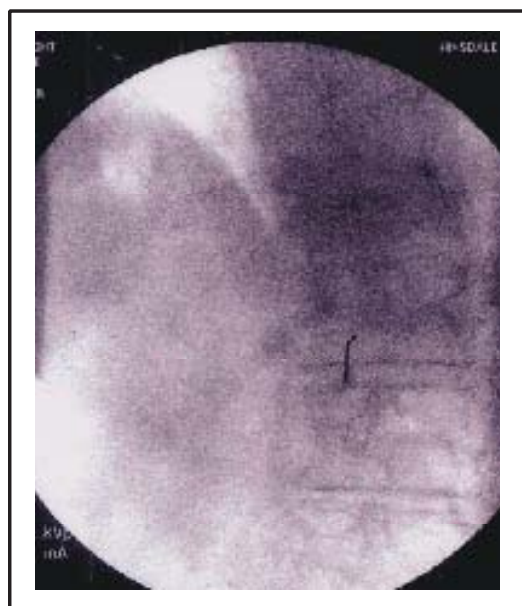

Fig. 1. Left oblique view with tip of the needle at the cephalad aspect of the left T12-L1 intervertebral foramen. The needle tip was positioned just below the pedicle of the T12 vertebral body without contacting the periosteum.

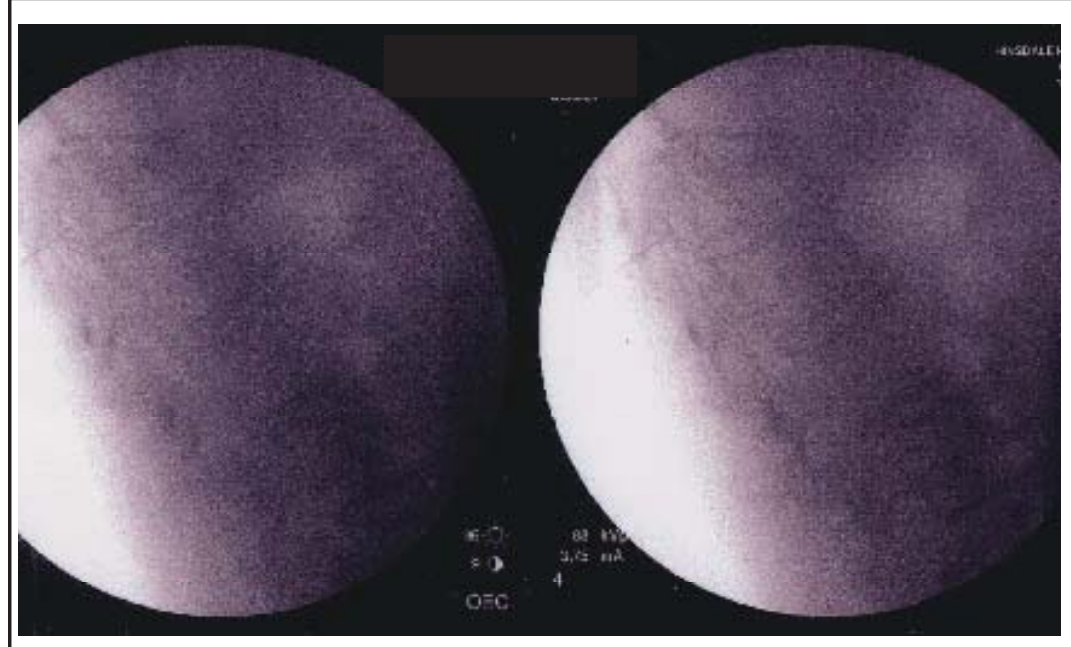

Fig. 3. Lateral fluoroscopic views demonstrating needle tip location just posterior to the vertebral body and near the inferior aspect of the pedicle. can, B. Braun) was inserted into the cephalad and anterior aspect of the left T12L1 foramen, utilizing a posterior oblique approach with a slight bend of the needle tip (Fig. 1). The needle tip was positioned just below the pedicle of the T12 vertebral body without contacting the periosteum. Small bore (Microbore, Lifeshield) extension tubing with $0.4 \mathrm{ml}$ of dead space was flushed with Isovue-300 to remove visible air bubbles and then was connected to the hub of the needle. An anterior posterior (AP) fluoroscopic view confirmed appro-

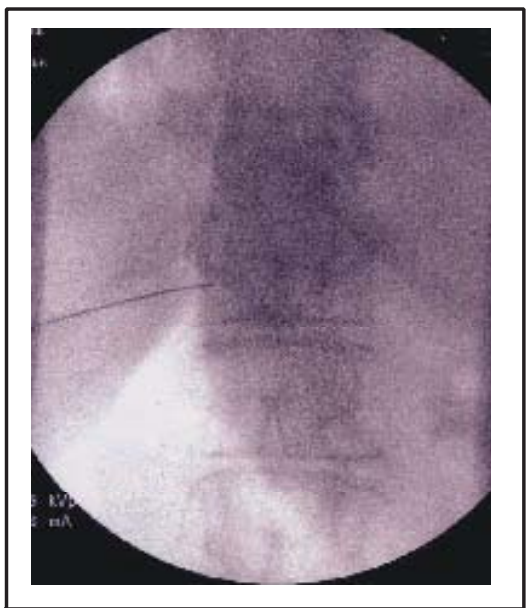

Fig. 2. Anterior posterior (AP)

fluoroscopic view confirmed needle tip placement at the superior aspect of the foramen, at the $6 o^{\prime}$ clock position under the pedicle.

priate needle tip placement at the 6 o'clock position under the pedicle (Fig. 2).

A lateral fluoroscopic view confirmed the needle tip location just posterior to the vertebral body (Fig. 3). Isovue was initially injected under lateral fluoroscopic visualization. The initial injection of Isovue revealed intravenous uptake. The contrast flow was sluggish and directed anteriorly towards the inferior vena cava. It took two to three heartbeats for the contrast to disappear. The needle was then withdrawn slightly within the foramen and further injection of Isovue revealed an outline of the nerve root and no intravenous uptake or evidence of intraarterial flow (Fig. 4). The fluoroscope was then positioned in an AP view and further injection of contrast revealed flow along the nerve root extending proximally into the epidural space medial to the T12 pedicle in the lateral recess (Fig. 5). The fluoroscope was adjusted to position the needle tip in the center of the fluoroscopic image. The injection of an additional 0.4 $\mathrm{mL}$ of Isovue contained in the tubing under live fluoroscopy revealed further extension of contrast cephalad in the epidural space. This was followed by the injection of a $3 \mathrm{~mL}$ mixture consisting $2 \mathrm{~mL}$ of Triamcinolone ( $25 \mathrm{mg}$ per $\mathrm{mL}$ ) with 1 $\mathrm{mL}$ of $1 \%$ Ropivacaine. A "washout" fluoroscopic image revealed dilution of the Isovue (Fig. 6).

The patient did not complain of any paresthesias during the procedure. She received conscious sedation ( $2 \mathrm{mg}$ midazolam and $50 \mathrm{mcg}$ fentanyl) and was responsive at all times during the injection. She reported the sensation of "air being let out" of her lower body and had a complete sensorimotor deficit below T10 within five minutes of completing the procedure. She did not become hypotensive at any time during or after the procedure, and an increase in blood pressure and heart rate were noted in the recovery area after the procedure. There was no evidence of neurological recovery that would have been expected after intrathecal injection of a local anesthetic. An MRI performed six hours after the procedure did not show any evidence of cord compression secondary to the compression fracture or an epidural hematoma. She was transferred to a neurologic intensive care unit for further monitoring. Consults were obtained with a neurosurgeon, neurologist, and an interventional radiologist. No treatment was recommend- 
ed or attempted other than supportive care and high dose intravenous steroids. An MRI performed two days later confirmed a spinal cord infarction from $\mathrm{T} 5$ to the conus medullaris. The patient has had no improvement in any of her neurological deficits in over four years. She continues to suffer from the same chronic chest wall pain that is not well-controlled with medication management.

\section{DISCUSSION}

This is the eighth case report of paraplegia following a thoracic or lumbar transforaminal epidural steroid injection. The previous reports did not provide fluoroscopic images of needle placement or dye flow. The presumed cause of these complications was interruption of blood supply to the spinal cord from the arteria radicularia magna (ARM-the artery of Adamkiewicz). This has been postulated to be secondary to either vascular trauma or the injection of particulate steroid into the artery causing an embolic effect.

The artery of Adamkiewicz is an enlarged radiculomedullary artery that anastomoses with the anterior spinal artery. There are multiple radicular arteries that supply blood flow to the spinal cord and enter the spinal cord at segmental lev-

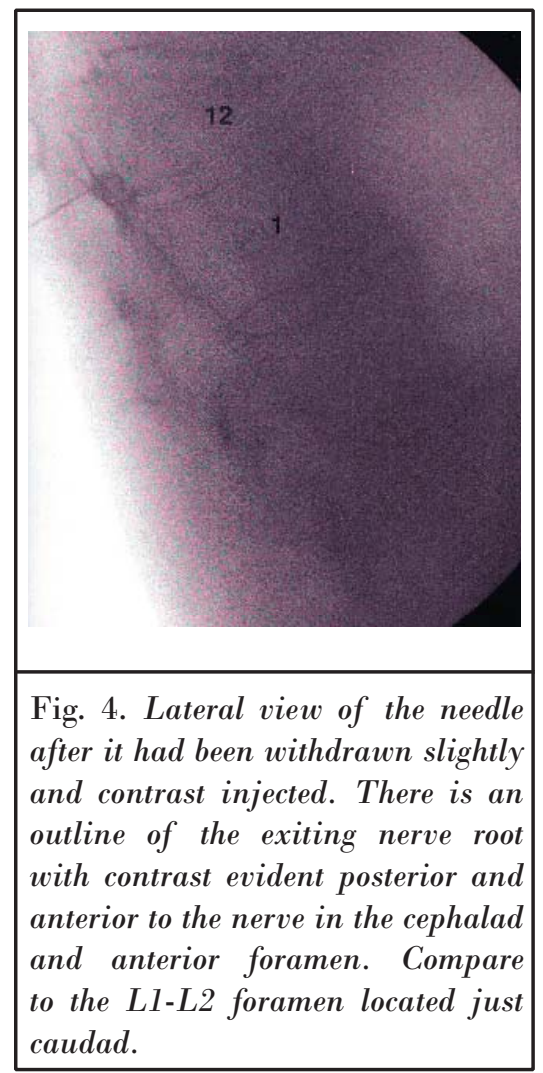

els. The posterior intercostal arteries arising from the aorta in the thoracic spine and the paired lumbar arteries that arise from the aorta in the lumbar spine form these segmental arteries. From the level of the sixth, seventh, or eighth posterior intercostal arteries, the vessels course around the middle of each vertebra. The lumbar arteries pass laterally and midline across the anterior and side of each vertebral body until they reach the intervertebral foramen (31). Each lumbar artery divides into a series of major branches (abdominal wall, intermediate or spinal canal, and the posterior body wall branches) just outside the level of the intervertebral foramina. The spinal canal branches divide into the anterior spinal canal, the nervous system, and the posterior spinal canal branches. The nervous system branches arise from the segmental artery just outside of the spinal canal. They course cephalad, reaching the superior edge of the adjacent nerve root, running along the dural nerve root sleeve for a short distance (32). These arteries supply blood to the spinal cord through anastomoses with the anterior spinal artery and by direct cord penetration. In the lower thoracic and lumbar spinal cord, blood perfusion is felt to be largely de-

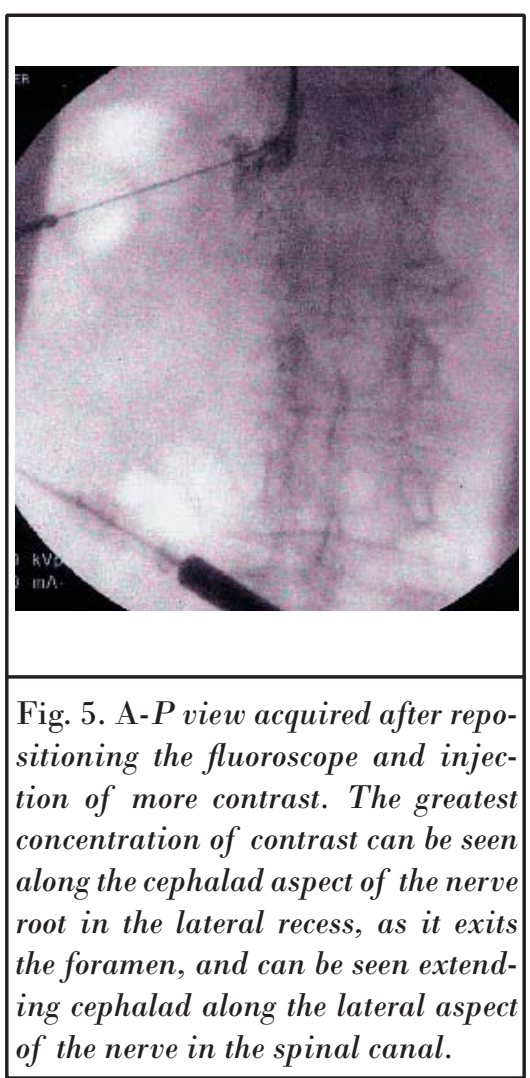

pendent on the ARM. Although recently questioned (33), the ARM is felt to be responsible for the majority of blood supply to the lower two-thirds of the anterior spinal cord. The ARM has been described in cadaveric studies to arise between $\mathrm{T} 5$ and L5, but recently was found along the lumbar nerve roots in greater than two-thirds of cadavers (34). That study also highlights the "remarkable variability of the ARM origin." The ARM enters the spinal canal on the left side 69 to 85 percent of the time, joins the nerve root at the foramen, and is located within the nerve root sleeve (35). The artery then courses medially through the rostral or midportion of the foramen closely juxtaposed to the dorsal root ganglion-ventral root complex at its rostral and ventral aspect (36). The average outer diameter of the artery at the foramen is $1.0 \mathrm{~mm}$.

In this case, there is evidence of flow of contrast in the usual pattern seen when performing this procedure. There is evidence of dilution of contrast by the injectate. The mechanism of injury could be secondary to arterial spasm and/or the development of an intimal flap. Both of these mechanisms could lead to stasis of flow, clot formation, and hypoperfusion. Arterial spasm leading to end-organ

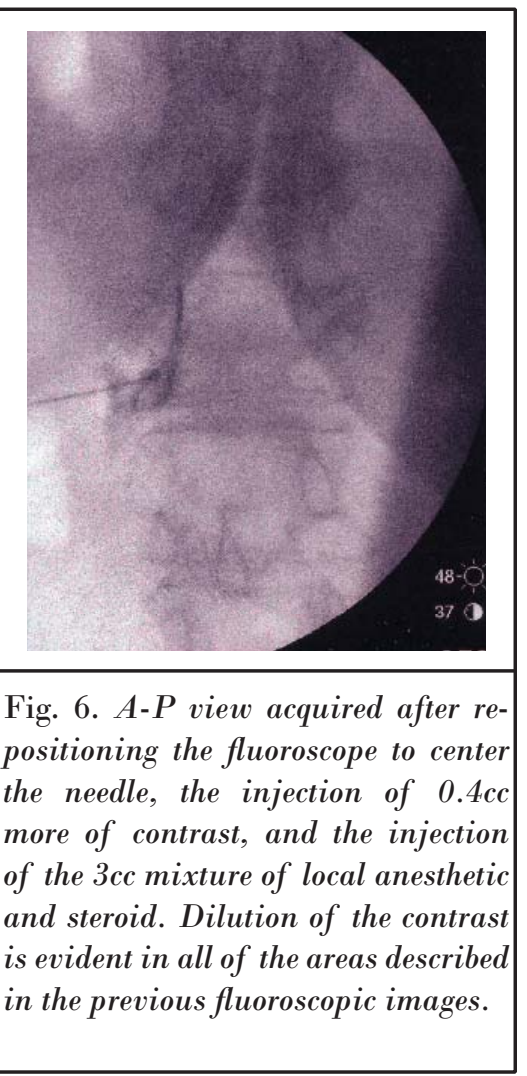


ischemia is a well known phenomenon as the arterial wall is highly muscular. Arterial spasm can lead to cerebral ischemia secondary to the effects of subarachnoid hemorrhage. Coronary artery vasospasm can lead to ischemia and myocardial injury and this variant of coronary ischemia is called Prinzmetal's angina (37). Coronary artery spasm causing pseudolesions occurs during angiography secondary to mechanical irritation (38). Radial artery spasm after cannulation is reported as high as $10 \%$ but rarely leads to sequelae secondary to collateral blood supply from the ulnar artery.

The development of an intimal flap after disruption of the muscular wall of the artery with the sharp bevel of the needle is also a plausible mechanism of injury. The tunica intima is one of the three layers of tissue in the wall of a blood vessel and is the innermost layer of the arterial wall consisting of endothelial cells and a subendothelial layer of loose connective tissue. The development of an intimal flap leading to arterial obstruction and rupture is a well known phenomenon. The flap can be secondary to mechanical trauma or atherosclerotic disease and has been described in the thoracic aorta, abdominal aorta, carotid arteries, vertebral arteries, coronary arteries, renal arteries (39), iliac arteries (40), and other vessels.

Another potential cause for cord infarction is occlusion of the ARM from an embolic event resulting from injection of particulate steroid directly into the artery. This mechanism of injury has been postulated in the literature regarding previously reported events. It has been shown that the steroids commonly used to perform this procedure are particulates that have the potential of causing microvascular occlusion. Light microscopy revealed that the particulates found in available triamcinolone preparations can range up to a size of 100 microns or larger (41). This is felt to be large enough to occlude arterioles, metarterioles, and some arteries.

For a steroid particle to cause an embolic effect in this specific case it would require that the bevel of the 22 -gauge needle be located within the ARM and remain in that position. The outer aspect of a 22-gauge needle and the outer diameter of the ARM at the level of the foramen are very close in size, based on anatomic studies. Additionally, the direction of the artery traveling around the posterior and lateral aspect of the vertebral body and then traveling with the nerve root would be perpendicular to the direction of the needle inserted utilizing a posterior and oblique approach to the foramen. The bevel would need to remain in place and the arterial lumen remain patent during the injection of contrast, positioning of the fluoroscope, changing of syringes, and the injection of the steroid/ local anesthetic mixture. Finally, a portion of the bevel would need to be extra-vascular to account for the existence of dye flow along the nerve root and in the epidural space. Another plausible circumstance that could account for this occurrence would be movement of the needle after the final injection of Isovue and before the injection of the steroid/local anesthetic mixture.

Unfortunately, there is no clear evidence as to which of these potential types of injury alone, or in combination, is responsible for spinal cord infarction from performing these injections. Expert opinions have been rendered regarding this specific case. One expert posited that it was a violation of the standard of care to have the tip of the needle in the anterior foramen at the level at which this injection was performed. This opinion was contradicted by the other experts. Another expert concluded that there was a violation of the standard of care because the fluoroscopic image (Fig. 4) was not positioned appropriately to detect flow in the ARM. This expert opined that had the fluoroscopic image been centered rather than at the upper aspect of the screen, flow would have been detected in the ARM, which turns cephalad after it enters the foramen. This does not take into account the fact that substantial dye flow was seen along the nerve root and in the epidural space. It also does not take into account that another injection of Isovue was performed under live fluoroscopy with the needle centered in the image without evidence of intra-arterial flow.

The injection of contrast is utilized to confirm the appropriate location of the needle tip and assumes that the medication injected after the contrast follow the same flow pattern. Contrast deposited within the subarachnoid space, the subdural space, or an intravenous or an intraarterial location would lead the physician to reposition the needle. Although described in the literature during a cervical transforaminal injection (27), the ease of detection of an intra-arterial injection is not known. The use of digital subtraction imaging which is purported to increase the ability to detect arterial flow, i.e. the sensitivity of the contrast injection, has been advocated as increasing the safety of these injections. If the mechanism of injury is not a result of an embolic event, the detection of an arterial injection would not necessarily lead to a decrease in the incidence of neurologic sequelae due to an interruption in vascular supply.

This also leads to the conclusion that the "safe triangle" is, in fact, a misnomer. Transforaminal injections historically have been taught to be performed in the "safe triangle" above the nerve root and at the six o'clock position under the pedicle (anterior-superior foramen). Performing a transforaminal injection using the "safe triangle" technique has been described in a teaching video as "the paradigm technique for blocking all segmental nerves above the lumbosacral segment." A review of literature published prior to 2000 , including book chapters and articles describing this technique, does not reveal any significant reference to the vascular structures within the foramen and no reference to the possibility of causing paraplegia through the mechanism of vascular injury or embolic phenomenon. Although the radiculomedullary arteries, including the ARM, travel in close juxtaposition to the nerve in the rostral and ventral portion of the foramen, the exact point at which they become invested with the nerve is likely to be variable. Any variability of the artery location in relation to the nerve would mean that the artery is at risk any time the needle is in the cephalad portion of the foramen. Avoidance of the nerve, which is one of the chief aims of the current method of performing transforaminal epidural steroid injections, might not ensure avoidance of this radiculomedullary artery. Additionally, it is obvious, based on anatomical studies, that the location of the ARM is highly variable as to the foramen through which it enters the spinal canal in the thoracic and lumbar spine. The case reports from Houten and Errico (18) reported a transforaminal epidural steroid injections at L3-4 in one case, L3-4 and L4-5 in another, and S1 in the third. Therefore, routine transforaminal epidural steroid injections in the superior and anterior aspect of the lumbar intervertebral foramen put the blood flow of the spinal cord at risk.

Because of the variability of the 
ARM, paraplegia must be recognized as a risk of transforaminal epidural steroid injections performed in the "safe triangle." This is true both in the thoracic and lumbar spine due to the high variability of the location of the ARM.

Transforaminal epidural steroid injections are valuable and important therapeutic and diagnostic procedures in the armamentarium of physicians specializing in managing spinal pain. Future research needs to be directed at alternative locations for, or alternative means of performing this efficacious procedure. Possible alternative locations for needle placement would be in the cephalad and posterior aspect of the intervertebral foramen or the caudad and anterior aspect of the foramen.

The putative reason for the higher success rate of transforaminal injections as compared to interlaminar or caudal injections is due to the ability to place the active medications in the ventral aspect of the epidural space. Therefore, the caudad and anterior aspect of the foramen might be the most efficacious location to place the needle during performance of a transforaminal injection. The trajectory of the needle for this approach is similar to the trajectory utilized for discography. Placement of the needle in a medial enough location (i.e. in, or just lateral to, the midpedicular line) requires a slightly more oblique view secondary to the location of the superior articular process of the inferior vertebra. In the experience of one of the authors, when utilizing this approach, contrast flow outlining the nerve root is consistent and comparable to that seen when performing this procedure in the "safe triangle," although the appearance along the inferior aspect of the nerve is dissimilar to the usual appearance. Additionally, contrast flow in the anterior epidural space is actually more widespread and medial as the dye does not tend to track along the cephalad aspect of the nerve in the lateral recess. As with discography, performing a transforaminal injection utilizing this technique may be difficult at the L5-S1 level due to the anatomy.

This approach can also be accomplished in the thoracic spine with a similar trajectory for the needle to that currently used for thoracic discography. This approach places the needle just medial to the head of the rib in the inferior foramen. A drawback to this approach is that it places the needle tip just posterior to the disc potentially increasing the risk of intradiscal injection. This might lead to an increased incidence of discitis.

A safer alternative means for performing this procedure might include the use of blunt tipped needles. A study revealed a significant difference between the ability of a blunt tipped needle, versus a needle with a sharp bevel, in penetrating the muscular wall of the renal artery (42). The use of blunt needles might allow physicians to place the needle for transforaminal injections at any location within the foramen without jeopardizing the blood supply to the spinal cord. When performing these injections, another safety measure that may be considered is the use of water soluble steroid solutions. This would include water soluble formulations of betamethasone and dexamethasone, which may improve the safety of drug injection associated with unintentional intravascular injection (41).

\section{ConcLusion}

This case report adds to the body of literature describing vascular injuries to the spinal cord following transforaminal epidural steroid injections. The vascular supply of the lumbar and thoracic spinal cord is quite variable, and the site of entry of the radiculomedullary artery through the intervertebral foramen is unpredictable. Alternative anatomic approaches to, or different means of, performing transforaminal epidural injections should be considered. It appears that the anatomic "safe triangle" is a misnomer.

\section{Author Affiliation:}

\section{Scott E. Glaser, MD}

Pain Specialists of Greater Chicago

100 Tower Drive, Suite 120

Burr Ridge, IL 60527

E-mail: sglaser@painchicago.com

\section{Frank Falco, MD}

Clinical Assistant Professor

Temple University Medical School

Philadelphia, PA

Medical Director

Mid Atlantic Spine \& Pain Specialists

139 East Chestnut Hill Road

Newark, DE 19713

E-mail: cssm01@aol.com

\section{References}

1. Boswell MV, Shah RV, Everett CR, Sehgal N, McKenzie-Brown AM, Abdi S, Bowman RC, Deer TR, Datta S, Colson JD, Spillane WF, Smith HS, Lucas-Levin LF, Burton AW, Chopra P, Staats PS, Wasserman RA, Manchikanti L. Interventional techniques in the management of chronic spinal pain: Evidence-based practice guidelines. Pain Physician 2005; 8:1-48.

2. Manchikanti L, Saini B, Singh V. Transforaminal epidural use of steroids. In Manchikanti L, Slipman CW, Fellows B (eds). Interventional Pain Management: Low Back Pain - Diagnosis and Treatment. ASIPP Publishing, Paducah, KY, 2002, pp 327-352.

3. O'Neill C, Derby R, Kenderes L. Precision injection techniques for diagnosis and treatment of lumbar disc disease. Semin
Spine Surg 1999; 11:104-118.

4. Boswell MV, Hansen HC, Trescot AM, Hirsch JA. Epidural steroids in the management of chronic spinal pain and radiculopathy. Pain Physician 2003; 6: 319-334.

5. Abdi S, Datta S, Lucas LF. Role of epidural steroids in the management off chronic spinal pain: A systematic review of effectiveness and complications. Pain Physician 2005; 8:127-144.

6. Riew KD, Yin Y, Gilula L, Bridwell KH, Lenke LG, Lauryssen C, Goette K. The effect of nerve-root injections on the need for operative treatment of lumbar radicular pain. J Bone Joint Surg AM 2000; 82:1589-1593.

7. Karppinen J, Malmivaara A, Kurunlahti M, Kyllonen E, Pienimaki T, Nieminen P, Ohinmaa A, Tervonen O, Vanharanta H. Periradicular infiltration for sciatica. Spine 2001;
26:1059-1067.

8. Karppinen J, Ohinmaa A, Malmivaara A, Kurunlahti M, Kyllonen E, Pienimaki T, Nieminen P, Tervonen O, Vanharanta H. Cost effectiveness of periradicular infiltration for sciatica. Spine 2001; 26:2587-2595.

9. Vad VB, Bhat AL, Lutz GE, Cammisa F. Transforaminal epidural steroid injections in lumbosacral radiculopathy: A prospective randomized study. Spine 2002; 27:1116.

10. Devulder J, Deene P, De Laat M, Van Bastelaere $M$, Brusselmans G, Rolly G. Nerve root sleeve injections in patients with failed back surgery syndrome: A comparison of three solutions. Clin J Pain 1999; 15: 132-135.

11. Thomas E, Cyteval C, Abiad L, Picot MC, Taourel P, Blotman F. Efficacy of transforaminal versus interspinous corticosteroid 
injection in discal radiculalgia: a prospective, randomised, double-blind study. Clin Rheumatol 2003; 22:299-304.

12. Lutz GE, Vad VB, Wisneski RJ. Fluoroscopic transforaminal lumbar epidural steroids: An outcome study. Arch Phys Med Rehabil 1998; 79:1362-1366.

13. Buttermann GR. The effect of spinal steroid injections for degenerative disc disease. Spine J 2004; 4:495-505.

14. Buttermann GR. Treatment of lumbar disc herniation: epidural steroid injection compared with discectomy. A prospective, randomized study. J Bone Joint Surg Am 2004; 86-A:670-679.

15. Botwin KP, Gruber RD, Bouchlas CG, Torres-Ramos FM, Sanelli JT, Freeman ED, Slaten WK, Rao S. Fluoroscopically guided lumbar transforaminal epidural steroid injections in degenerative lumbar stenosis: an outcome study. Am J Phys Med Rehabil 2002; 81:898-905.

16. Bush K, Hillier S. Outcome of cervical radiculopathy treated with periradicular/ epidural corticosteroid injections: A prospective study with independent clinical review. Eur Spine J 1996; 5:319-325

17. Cyteval C, Thomas E, Decoux E, Sarrabere MP, Cottin A, Blotman F, Taourel P. Cervical radiculopathy: Open study on percutaneous periradicular foraminal steroid infiltration performed under $\mathrm{CT}$ control in 30 patients. AJNR Am J Neuroradiol 2004; 25: 441-445.

18. Houten JK, Errico TJ. Paraplegia after lumbosacral nerve root block: Report of three cases. Spine J 2002; 2:70-75.

19. Elias M. A rare cause of radiculopathy following transforaminal epidural steroid injection. Pain Clinic 1998; 11:159-160.

20. Brouwers PJ, Kottink EJ, Simon MA, Prevo RL. A cervical anterior spinal artery syndrome after diagnostic blockade of the right C6-nerve root. Pain 2001; 91:397399.

21. Nash TP. Comment on A cervical anterior spinal artery syndrome after diagnostic blockade of the right C6-nerve root. Pain 2002; 91:217-218.
22. Stohr M, Mayer K. Nerve-root damage from local injections. Dtsch Med Wochenschr 1976; 101:1218-1220.

23. Milhaud D, Heroum C, Charif M, Saulnier P, Pages M, Blard JM. Dural puncture and corticotherapy as risks factors for cerebral venous sinus thrombosis. Eur J Neurol 2000; 7:123-124.

24. Schultz D. Risk of transforaminal epidural injections. Pain Physician 2004; 7:289290.

25. Helm S, Jasper J, Racz G. Complications of transforaminal epidural injections. Pain Physician 2003; 6:389-390.

26. Young WF. Transient blindness after lumbar epidural steroid injection. Spine 2002; 27:E476-E477.

27. Baker R, Dreyfuss P, Mercer S, Bogduk N. Cervical transforaminal injection or corticosteroids into a radicular artery: A possible mechanism for spinal cord injury. Pain 2003; 109:211-215.

28. Rozin L, Rozin R, Koehler SA, Shakir A, Ladham S, Barmada M, Dominick J, Wecht CH. Death during transforaminal epidural steroid nerve root block $\left(\mathrm{C}_{7}\right)$ due to perforation of the left vertebral artery. Am J Forensic Med Pathol 2003; 24:351-355.

29. Huntoon MA, Martin DP. Paralysis after transforaminal epidural injection and previous spinal surgery. Reg Anesth Pain Med 2004; 29:494-495.

30. Windsor RE, Falco FJE: Paraplegia following selective nerve root blocks. ISIS Scientific Newsletter 2001; 4:53-54.

31. Crock HV, Yoshizawa H. Origin of arteries supplying the vertebra column. In The blood supply of the vertebral column and spinal cord in man. RR Donnelly \& Sons, Chicago, 1977, pp 4-5.

32. Crock HV, Yoshizawa H. Origins of arteries supplying the meninges and spinal cord. In The blood supply of the vertebral column and spinal cord in man. RR Donnelly \& Sons, Chicago, 1977, p 26.

33. Griepp RB, Ergin MA, Galla JD, Lansman S, Khan N, Quintana C, McCollough J, Bodian C. Looking for the Artery of Adamkiewicz: a quest to minimize paraplegia after operations for aneurysms of the descending thoracic and thoracoabdominal aorta. J Thorac Cardiovasc Surg 1996; 112:12021215.

34. Biglioli P, Spirito R, Roberto M, Grillo F, Cannata A, Parolari A, Maggioni M, Coggi $G$. The anterior spinal artery: The main arterial supply of the human spinal cord a preliminary anatomic study. I Thorac Cardiovasc Surg 2000; 119:276-27

35. Lu J, Ebraheim NA, Biyani A, Brown JA, Yeasting RA. Vulnerability of great medullary artery. Spine J 1996; 21:1852-1855.

36. Alleyne CH Jr, Cawley CM, Shengelaia GG, Barrow DL. Microsurgical anatomy of the artery of Adamkiewicz and its segmental artery. J Neurosurg 1998; 89:791-795.

37. Yasue, H, Ogawa, H. Endothelial Dysfunction and Coronary Artery Spasm. Am J Cardiol 2000; 85:26-30.

38. Doshi, S, Shiu MF. Coronary pseudolesions induced in the left anterior descending and right coronary artery by the angioplasty guidewire. Int / Cardiol 1999; 68: 337-342.

39. Paul JL, Otal P, Perreault P, Galinier P, Baunin C, Puget C, Joffre F, Rosseau H. Treatment of posttraumatic dissection of the renal artery with endoprosthesis in a 15 year old girl. I Trauma-Injury Infection and Crit Care 1999; 47:169-172.

40. Tsai F, Wang C, Fang J, Lin PJ, Kao C, Hsieh $\mathrm{H}$, Chu J, Chen R, Chang C. Isolated common iliac artery occlusion secondary to atherosclerotic plaque rupture from blunt abdominal trauma: case report and a review of the literature. J Trauma-Injury Infection and Crit Care 1997; 42:133-136.

41. Tiso RL, Cutler T, Catania JA, Whalen K. Adverse central nervous system sequelae after selective transforaminal block: the role of corticosteroids. Spine / 2004: 4:468-474.

42. Heavner JE, Racz GB, Jenigiri $B$, Lehman T, Day M. Sharp versus blunt needle: A comparative study of penetration of internal structures and bleeding in dogs. Pain Practice 2003; 3, 226-231. 